\title{
Analysis of the profile of cardiovascular risk in Brazilian schoolchildren: metabolic and behavioral indicators
}

Daniela Casagrande $e^{1,2}$

https://orcid.org/0000-0001-9385-0853

Alceu Afonso Jordão Júnior ${ }^{2}$

https://orcid. org/0000-0003-1288-0802

Paulo Henrique Waib'

https://orcid.org/0000-0003-2339-4615

\begin{abstract}
Objective: There is evidence demonstrating that cardiovascular diseases (CVD) manifesting during adulthood result from an intense interaction among risk factors that may have originated during childhood and adolescence. To compare the prevalence and clustering of cardiovascular risk factors in Brazilian schoolchildren with a 15-year interval between samples. Subjects and methods: A crosssectional analysis based on the scores for cardiovascular risk factors was used to investigate 1,232 Brazilian schoolchildren of both sexes aged 12 to 18 years. The data of 596 schoolchildren of the 2000 sample were compared to those of 636 schoolchildren of the 2015 sample. Results: The prevalence of physical inactivity and abdominal obesity increased exponentially in both sexes from 2000 to 2015 . The score for the clustering of cardiovascular risk factors showed that in 2000 the adolescents were exposed to 1 cardiovascular risk factor (31.7\%), while in 2015 the greatest percentage was assigned to the category of 3 or more cardiovascular risk factors $(34.9 \%), p<0.001$. Conclusion: The present results demonstrate a high prevalence of exposure to health risk behaviors of the adolescents studied over time. Considering the presence of modifiable risk factors, preventive measures regarding life style are essential. Arch Endocrinol Metab. 2020;64(6):679-86
\end{abstract}

Keywords

Adolescent behavior; cardiovascular risk factors; cardiovascular diseases; prevention

\author{
${ }^{1}$ Centro de Pesquisa em \\ Hipertensão e Metabolismo, \\ Faculdade de Medicina de \\ Marília, Marília, SP, Brasil \\ ${ }^{2}$ Departamento de Ciências da \\ Saúde, Faculdade de Medicina de \\ Ribeirão Preto, Universidade de São \\ Paulo, Ribeirão Preto, SP, Brasil
}

Correspondence to:

Daniela Casagrande

Departamento de Ciências da Saúde, Faculdade de Medicina de Ribeirão

Preto, Universidade de São Paulo

Av. Bandeirantes, 3.900, Anexo A

14049-900 - Ribeirão Preto, SP, Brasil casagrande.dani@usp.br

Received on Jan/1/2020

Accepted on Apr/27/2020

DOI: 10.20945/2359-3997000000269

\section{INTRODUCTION}

$\mathrm{C}$ ardiovascular diseases (CVD) currently represent $\checkmark$ the first cause of death and premature disability in the world. In Brazil, CVD cause 30\% of all deaths, $50 \%$ of which involving adults aged 30 to 60 years, i.e., in the full productive phase of life. This causes high public health costs due to hospitalization, procedures and early retirement (1).

The changes in the nutritional profile of the entire population evidenced in the last decades, known as the process of nutritional transition, are characterized by the decrease of innutrition and the increase of the rates of overweight and obesity in all ages, associated with the risk factors that predispose to the onset of CVD and social changes, economic and demographic effects of the country's development process. The World Health Organization (WHO) proposes conducts for the control and prevention of risk factors linked to CVD in all age ranges, including childhood and adolescence (2).

The prevalence of overweight among adolescents has reached significant levels in recent years. At the beginning of the 1990s, $7.7 \%$ of Brazilian adolescents were overweight. In the 2000s, other studies developed in the country showed higher values. Data from the Family Budgets Survey (POF in the Portuguese acronym), carried out in 2002-2003, highlighted that $16.7 \%$ of adolescents aged 10 to 19 years were overweight (3). The National Survey on Demography and Health (PNDS) conducted in 2006 showed that $21.6 \%$ of adolescents aged 15 to 19 years were overweight and $4.4 \%$ of them obese (4). Data from one of the largest National Studies of Cardiovascular Risk in Adolescents (ERICA in the Portuguese acronym) (5) have pointed out that a significant parcel of young Brazilians aged 11 to 17 years show changes in plasma 
lipids, that $33.9 \%$ are overweight, and that $9.6 \%$ are already hypertensive.

The adolescence phase is considered to be a critical period for the beginning or persistence of habits that will reflect on the adult phase. Despite the importance of this topic, few studies have evaluated the clustering of cardiovascular risk factors (CVRF) in significant samples of young Brazilians. In view of the above considerations, the objective of the present study was to determine the prevalence and clustering of CVRF in representative samples of adolescent schoolchildren in the municipality of Marília, São Paulo, Brazil, over a period of 15 years in order to investigate the evolution of these factors over time.

\section{SUBJECTS AND METHODS}

We analyzed cross-sectionally the anthropometric, pressure, glycemic and sociodemographic data collected in 2000 and 2015 of a representative sample of adolescent schoolchildren enrolled in public and private schools of Marília, a city located in the State of São Paulo, in the southeastern region of Brazil. It has a human development index of 0.798 and an estimated population of 230 thousand inhabitants (9,976 adolescents enrolled in high school in 2015). All reasonable efforts were made to identify a sample of schoolchildren that was representative of the population as a whole. The study was authorized by the Municipal Secretary Office of Education of Marília and was approved by the Research Ethics Committee of the Faculty of Medicine of Marilia (CAAE 32063814.6.0000.5413), with financial support from the Coordination of Improvement of Higher Level Personnel (Capes in the Portuguese acronym).

Schoolchildren aged 12 to 18 years of both sexes whose parents or tutors gave written informed consent were included in the study. Adolescents with organic insufficiency, debilitating chronic diseases, type 1 diabetes mellitus or a physical/mental deficiency that would prevent their participation and pregnant girls were excluded from the study. The total number of participants was similar for the year $2000(\mathrm{n}=596)$ and $2015(\mathrm{n}=636)$.

Anthropometric measurements were obtained by the same group of trained evaluators in both years. The weight was measured with calibrated digital scale with capacity for $150 \mathrm{~kg}$ with precision of $0,1 \mathrm{~kg}$, with the subject fasting, standing up with arms along the body, barefoot, and wearing light clothing. The height was determined by means of a fixed ruler on the wall with a scale in centimeters ( 2 meters in length with an accuracy of $0.1 \mathrm{~cm}$ ) with students barefoot, standing straight on a smooth surface, with their back to the ruler and with feet close together. Body mass index (BMI) was calculated by the formula BMI $=$ weight $(\mathrm{kg}) /$ height $^{2}$ (m). Waist circumference (WC) was measured at the end of an expiration in the midpoint between the costal margin and the iliac crest using an inextensible anthropometric tape with $0.1 \mathrm{~cm}$ precision (6).

Nutritional status was defined on the basis of the BMI according to WHO criteria for adolescents: $\underline{\text { low }}$ weight $(<3$ rd percentile), overweight $(\geq 85$ th $<97$ th percentile) and obesity ( $\geq 97$ th percentile), adjusted for sex and age (7).

Abdominal adiposity was defined according to the criteria of the International Diabetes Federation (IDF) for adolescents aged 12 to 16 years ( $\geq 90$ th percentile), adjusted for age and sex. The IDF criteria for adults were used for adolescents aged $>16$ years $(\geq 80 \mathrm{~cm}$ for women and $90 \mathrm{~cm}$ for men) (8).

Blood pressure was measured by the oscillometric method using an automatic device with accuracy from 0 to $299 \mathrm{mmHg}$ and a cuff of the appropriate size for the arm circumference of adolescents. A single measurement was made with the subject sitting and with the left arm resting at the height of the heart after a 5 -minute rest. Values $\geq$ the 90th percentile were considered for the diagnosis of high blood pressure in adolescents aged $\leq 16$ years according to sex and height $(9)$ and values $\geq 130 \times 85 \mathrm{mmHg}$ were considered for adolescents older than 16 years $(8)$. Mean arterial pressure [MAP $=\mathrm{SAP}+(\mathrm{DAP} \times 2) / 3$ ] was used for statistical analysis regarding its correlation with other risk factors.

Glycemia was determined in samples venous blood and capillary blood collected in the school environment itself after an 8 hour fast. For the comparison of the 2000 glycemia values (venous blood) and the 2015 values (capillary blood) we used a $15 \%$ correction of the capillary measure value (10). Hyperglycemia was diagnosed using a value $\geq 100 \mathrm{mg} / \mathrm{dL}$ or based on a confirmed diagnosis of type 2 diabetes mellitus (8).

The sociodemographic data were collected in a personal interview in the form of a standardized questionnaire, previously tested with questions regarding: socioeconomic data, regular smoking habit and alcohol consumption. Alcohol consumption was identified among the adolescents and was considered to be a risk behavior when the subject reported 
consumption during the last 30 days (as "yes" for 1 or more days). The level of physical activity was determined using the International Physical Activity Questionnaire (IPAQ) (11), short version. According to the IPAQ results, the subjects were divided into two major groups: active and physical inactivity.

A clustering score was used to define the presence of any combination of cardiovascular risk factors. For the analysis of continuous variables, the procedures of descriptive statistics were used and, subsequently, to identify any differences between genders, Student's t-test. The score ranged from zero to 3 (zero $=$ no exposure, 1 = exposure to one factor; 2 = exposure to two factors, and $3=$ exposure to three or more risk factors). Descriptive statistical analysis of the data was processed with the R Core Team software, 2016. The chi-square test $\left(\chi^{2}\right)$ was used to determine significant differences between categorical variables. Relative risk was determined in order to assess exposure and outcome, with a $95 \%$ level of significance of the confidence interval. The level of significance was set at $5 \%(\mathrm{p}<0.05)$ in all analyses.

\section{RESULTS}

Of the 1,232 participating adolescents, 596 were studied in 2000 and 636 in 2015. The distribution of proportion was $54.2 \%$ vs. $60.7 \%$ for girls and $45.8 \%$ vs. $39.3 \%$ for boys. Mean age was $15.1( \pm 1.1)$ vs. 15.3 ( \pm 1.1) years). The baseline characteristics of the adolescents are described in table 1.

The prevalence of CVRF is presented in table 2 . Comparison of the 2000 and 2015 samples revealed that the most prevalent factor was physical inactivity $(66.5 \%)$ and the least prevalent was smoking (2.7\%). There was an evident increase over time in the prevalence of abdominal adiposity physical inactivity and risky alcohol consumption.

Table 1. Mean values and standard deviation for information associated with risk factors predisposing to cardiovascular disease $(n=1,232)$

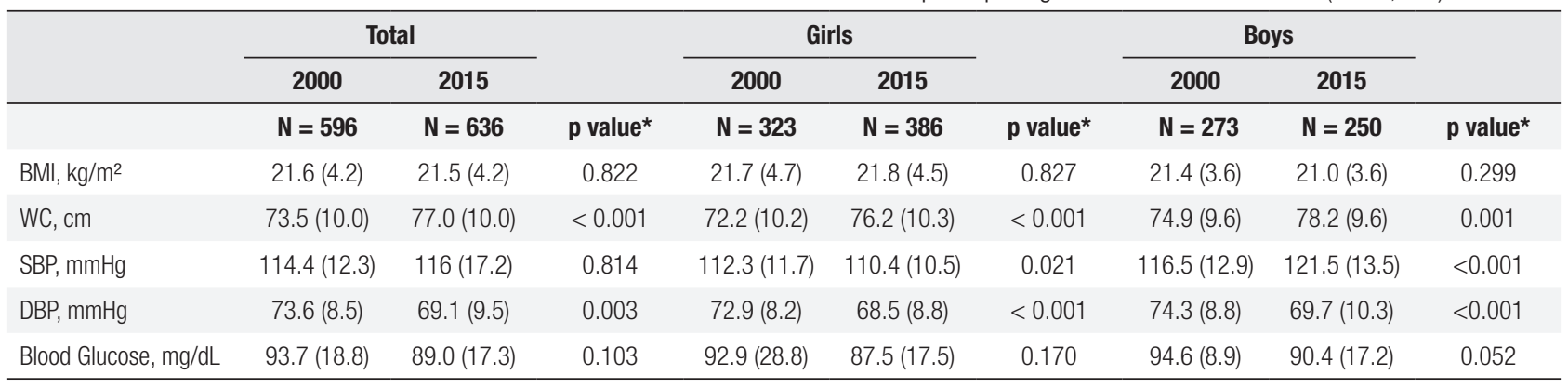

* $p$ value of the Student's t-test.

BMI: body mass index; WC: waist circumference; SBP: systolic blood pressure; DBP: diastolic blood pressure.

Table 2. Proportion (n/\%) of adolescents with factors predisposing to cardiovascular risk (2000 and 2015 comparison)

\begin{tabular}{|c|c|c|c|c|c|c|c|c|c|}
\hline & \multicolumn{2}{|c|}{ Total } & & \multicolumn{2}{|c|}{ Girls } & & \multicolumn{2}{|c|}{ Boys } & \\
\hline & 2000 & 2015 & & 2000 & 2015 & & 2000 & 2015 & \\
\hline Risk factor & $N=596$ & $N=636$ & p value* & $N=323$ & $N=386$ & p value* & $N=273$ & $N=250$ & p value* \\
\hline Abdominal adiposity & $179(30)$ & 305 (48) & $<0.001$ & $131(40.6)$ & $221(57.3)$ & $<0.001$ & $48(17.6)$ & $84(33.6)$ & $<0.001$ \\
\hline Overweight & $61(10.2)$ & $94(14.8)$ & 0.020 & $36(11.1)$ & $59(15.3)$ & 0.133 & $25(9.2)$ & $35(14.0)$ & 0.111 \\
\hline Obesity & $48(8.1)$ & $55(8.6)$ & 0.784 & $26(8.0)$ & $40(10.4)$ & 0.354 & $22(8.1)$ & $15(6.0)$ & 0.455 \\
\hline $\begin{array}{l}\text { Increased blood } \\
\text { pressure }\end{array}$ & $167(28)$ & $166(26.1)$ & 0.488 & $76(23.5)$ & $67(17.4)$ & 0.052 & $92(33.3)$ & 99 (39.6) & 0.162 \\
\hline Hyperglycemia & $72(18,2)$ & $135(21.2)$ & 0.278 & $36(11.1)$ & 68 (17.6) & 0.347 & $36(13.2)$ & $67(26.8)$ & 0.726 \\
\hline Sedentarism & $196(32.9)$ & $423(66.5)$ & $<0.001$ & $137(42.2)$ & $293(75.9)$ & $<0.001$ & $59(21.6)$ & $130(52.0)$ & $<0.001$ \\
\hline Smoking & $81(13.6)$ & $17(2.7)$ & $<0.001$ & $35(10.8)$ & $7(1.8)$ & $<0.001$ & $46(16.8)$ & $10(4.0)$ & $<0.001$ \\
\hline Alcohol consumption & $41(6.9)$ & $154(24.2)$ & $<0.001$ & $13(4.0)$ & $84(21.8)$ & $<0.001$ & $28(10.3)$ & $70(28.0)$ & $<0.001$ \\
\hline
\end{tabular}

* $p$ value of the chi-square test.

Altered blood pressure $=$ values $\geq$ the 90th percentile according to sex and height. A value $\geq 130 \times 85 \mathrm{mmHg}$ was considered to be arterial hypertension for adolescents older than 16 years.

Sedentarism: $<90 \mathrm{~min} /$ week physical activity ${ }^{11}$. Smoking = equivalent to smoking one or more cigarettes a day. Alcohol consumption = equivalent to the intake of one dose or more per day. 
The proportion of adolescents with a cardiovascular risk according to sex in shown in table 2. Physical inactivity was the most prevalent factor among girls in both studies ( $42.2 \%$ vs. $75.9 \%)$. In 2000 , alcohol consumption $(4.0 \%)$ was the risk of lowest percentage, while in 2015 the lowest risk factor was smoking (1.8\%). Among boys, despite the lack of statistical significance, the most evident CVRF was the increase in blood pressure in 2000 (33.3\%) and physical inactivity in 2015 $(52.2 \%)$. In the 2000 sample, obesity was the lowest CVRF, while smoking was the lowest risk factor in 2015, as also observed for girls. When the data were stratified by sex, the increase in abdominal adiposity, physical inactivity and alcohol consumption continued to be the most important and significantly more prevalent CVRF.

The CVRF clustering score is presented in table 3. No CVRF was observed in $17.3 \%$ of the entire sample investigated. When the score was stratified according to year of study, an impressive decline was noted in this proportion, with a significant decrease from $27.3 \%$ in 2000 to $7.9 \%$ in 2015 . In 2000 , the participants with 1 risk factors corresponded to the greatest percentage of the score $(31.7 \%)$, whereas in 2015 , the greatest percentage was of 3 or more risk factors $; 4.9 \%)$. The analysis stratified by year and sex revealed a significant modification $(\mathrm{p}<$ 0.0001 ) of the prevalence of CVRF in both sexes. Among the 2000 girls, the highest percentages corresponded to categories 1 and 2 of the CVRF score (58.2\%), whereas in $2015,69.2 \%$ already belonged to the categories of 2 and 3 or more CVRF. Among the boys, the result was even more worrying, with $62.6 \%$ being classified into categories 0 and 1 of CVRF in 2000, as opposed to a majority of subjects $(61.6 \%)$ with 2 or more CVRF in 2015 (Table 3).

Figure 1 illustrates the frequency of each risk factor within the score. Physical inactivity was the most prevalent factor in the categories of 1,2 and 3 or more CVRF in both years. Abdominal adiposity was the most outstanding risk factor in both years, with a growing proportion. Among subjects with 3 or more risk factors, abdominal adiposity, increased blood pressure and physical inactivity were the most prevalent.

Analysis of the prevalence ratio did not reveal an association between physical inactivity and increased blood pressure. With similar results, both in 2000 and 2015 , the adolescents with increased WC had a 1.8 fold higher risk (95\% CI 1.39-2.39) to have an increase in blood pressure compared to those with WC within the indicated values.

Table 3. Clustering scores for cardiovascular risk factors

\begin{tabular}{|c|c|c|c|c|c|c|c|}
\hline \multirow{3}{*}{ Number of risk factors ${ }^{a}$} & \multicolumn{6}{|c|}{ Group } & \multirow{3}{*}{ p value ${ }^{\star}$} \\
\hline & \multicolumn{2}{|c|}{ General $n=1,232$} & \multicolumn{2}{|c|}{2000 Group n = 596} & \multicolumn{2}{|c|}{2015 Group n = 636} & \\
\hline & n & $\%$ & $\mathbf{n}$ & $\%$ & $\mathbf{n}$ & $\%$ & \\
\hline 0 & 213 & 17.3 & 163 & 27.3 & 50 & 7.9 & \multirow[t]{4}{*}{0.001} \\
\hline 1 & 354 & 28.7 & 189 & 31.7 & 165 & 25.9 & \\
\hline 2 & 323 & 26.2 & 124 & 20.8 & 199 & 31.3 & \\
\hline 3 & 342 & 27.8 & 120 & 20.1 & 222 & 34.9 & \\
\hline
\end{tabular}

* $p$ value of the chi-square test.

${ }^{a}$ Clustering score for cardiovascular risk factors defined as the sum of any combination of the following factors: high blood pressure, hyperglycemia, smoking, excessive alcohol consumption, sedentarism, overweight and/or obesity and central obesity.

Table 4. Clustering scores for cardiovascular risk factors stratified by sex and year

\begin{tabular}{|c|c|c|c|c|c|c|c|c|c|c|}
\hline \multirow{3}{*}{ Number of risk factors ${ }^{a}$} & \multicolumn{4}{|c|}{ Girls } & \multirow{3}{*}{ p value* } & \multicolumn{4}{|c|}{ Boys } & \multirow{3}{*}{ p value* } \\
\hline & \multicolumn{2}{|c|}{$\begin{array}{l}2000 \text { Grupo } \\
(n=332)\end{array}$} & \multicolumn{2}{|c|}{$\begin{array}{l}2015 \text { Group } \\
(n=386)\end{array}$} & & \multicolumn{2}{|c|}{$\begin{array}{l}2000 \text { Group } \\
(n=284)\end{array}$} & \multicolumn{2}{|c|}{$\begin{array}{l}2015 \text { Group } \\
(n=250)\end{array}$} & \\
\hline & $\mathbf{n}$ & $\%$ & $\mathbf{n}$ & $\%$ & & $\mathbf{n}$ & $\%$ & $\mathbf{n}$ & $\%$ & \\
\hline 0 & 69 & 21.4 & 21 & 5.4 & \multirow[t]{4}{*}{0.001} & 94 & 34.4 & 29 & 11.6 & \multirow[t]{4}{*}{0.001} \\
\hline 1 & 112 & 34.7 & 98 & 25.4 & & 77 & 28.2 & 67 & 26.8 & \\
\hline 2 & 76 & 23.5 & 128 & 33.2 & & 48 & 17.6 & 71 & 28.4 & \\
\hline 3 & 66 & 20.4 & 139 & 36 & & 54 & 19.8 & 83 & 33.2 & \\
\hline
\end{tabular}

* $p$ value of the chi-square test.

a Clustering score for cardiovascular risk factors defined as the sum of any combination of the following factors: high blood pressure, hyperglycemia, smoking, excessive alcohol consumption, sedentarism, overweight and/or obesity and central obesity. 
A

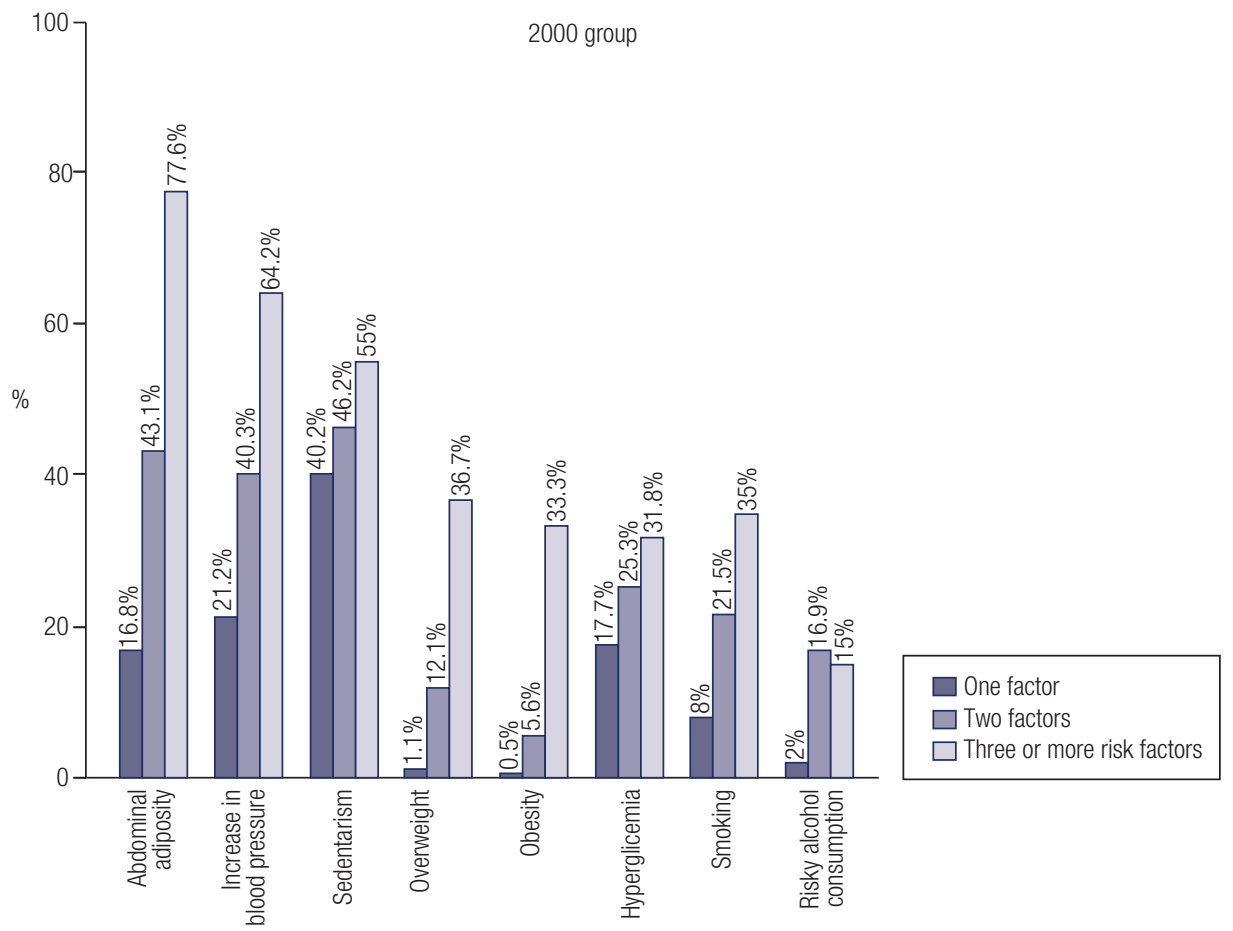

B

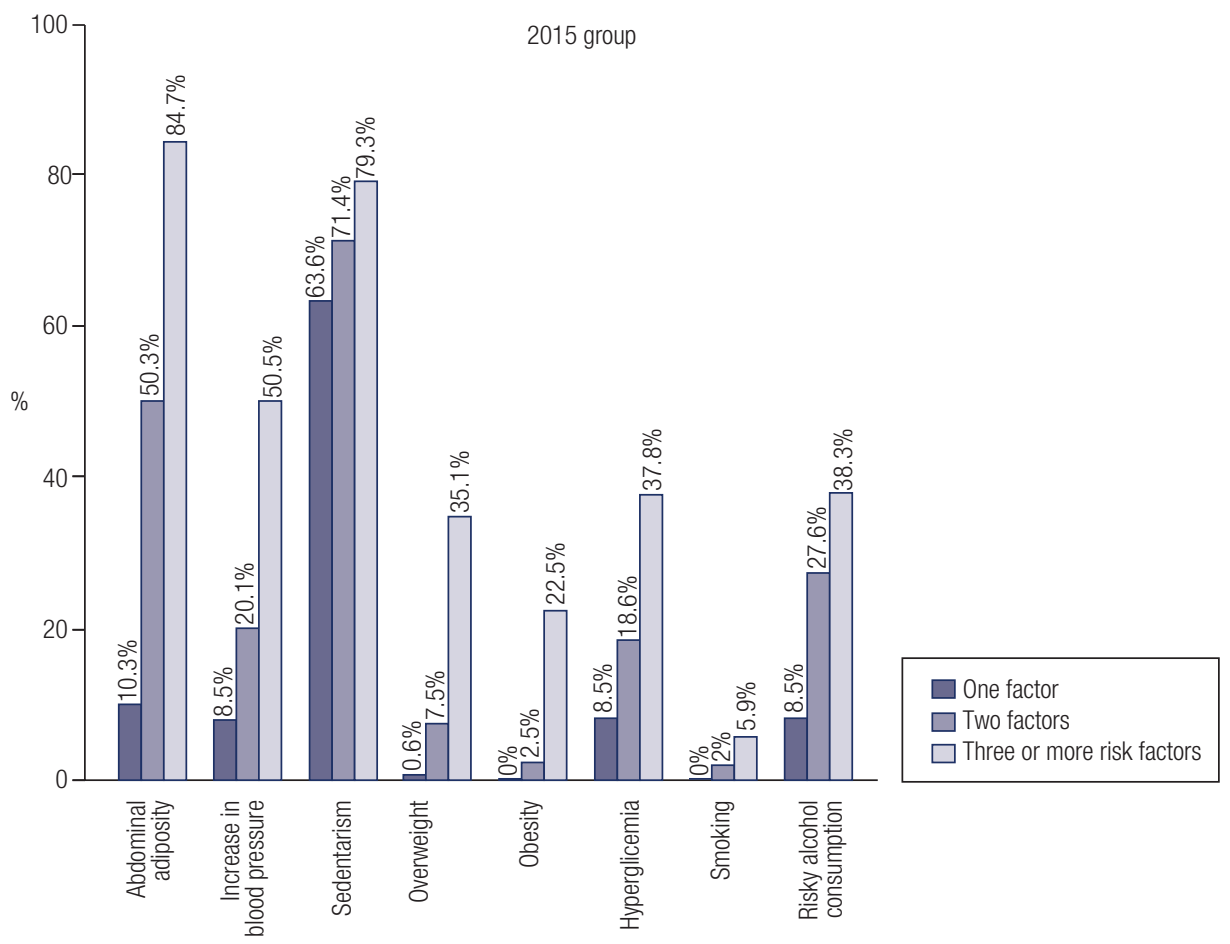

Figure 1. (A) Prevalence of each cardiovascular risk factors according to category of clustering score in 2000. (B) Prevalence of each cardiovascular risk factors according to category of clustering score in 2015.

\section{DISCUSSION}

The present study describes the evolution of CVRF in samples of Brazilian adolescents over a period of 15 years. The risk factors associated with behavioral aspects such as physical inactivity and increased abdominal adiposity were the most prevalent. As a source of concern, the data show a modification of the lifestyle of adolescents with possible deleterious consequences 
associated with obesity such as dyslipidemia, cancer, arterial hypertension, atherosclerotic diseases, and nonalcoholic fatty liver disease (12).

The CVRF score revealed a high prevalence of health risk behaviors among adolescents over the years, as also reported in other similar studies all the world (13). The results of this survey indicate that in 2000 most adolescents were exposed to 1 cardiovascular risk factor, whereas in 2015 the highest percentage of adolescents reached the category of 3 or more CVRF. Sanchez and cols. (14), reported that almost $80 \%$ of US adolescents aged 11 to 15 years presented health risk behavior and only $2 \%$ met guidelines for physical activity and healthy eating. Hardy and cols. (15) reported that more than half of those assessed had 3 or more cardiovascular risk factors. With similar results, Plotnikoff and cols. (16), analyzing Canadian adolescents aged 11-17 years, found that $43 \%$ of boys and $53 \%$ of girls had 2 or more cardiovascular risk factors. The greater the amount of clustered risk factors, the higher the probability of the early onset and development of cardiovascular diseases (13).

Another result to be highlighted is the modification of the number of adolescents with no CVRF from $2000(27.3 \%)$ to 2015 (7.9\%). Other authors have also observed a low percentage of adolescents with CVRF (13) suggesting that sedentary adolescents tend to adopt simultaneously an inadequate diet and the use of alcohol and tobacco. In addition to deaths due to cardiovascular accidents, more than one third of cancer deaths in the world are attributed to modifiable risk factors such as smoking, physical inactivity, alcohol and tobacco consumption, inappropriate eating habits, and excess weight (17), these being the most prevalent factors in the $\mathrm{p}$ resent study. Among the modifiable causes of cancer in Brazil, 3.8\% of all annual diagnoses are attributed to excess weight, with an increase to $4.6 \%$ predicted by 2025 (18). Although this information involves another age range, it becomes relevant due to the difficulty to change habits among children and adolescents.

Several studies (19-20) have reported a $10 \%$ to $25.9 \%$ variation in the prevalence of excess weight among adolescents. A significant change in excess weight (excess weight + obesity) from $18.3 \%$ in 2000 to $23.4 \%$ in 2015 ( $\mathrm{p}<0.27$ ) was observed in the present study. In the United States, estimates from the National Health and Nutrition Survey (NHANES IV) (21) showed that in the early 2000s, in the 12-19 age group, overweight increased from $14.8 \%$ to $18.3 \%$ in boys and from $14.8 \%$ to $16.4 \%$ in girls. At the same time in Brazil, the prevalence of overweight in the 10 to 19 years' age group was $18.0 \%$ in boys and $15.4 \%$ in girls (3). Adiposity rates also increased from $30 \%$ to $48 \%$ in 2015 . These results agree with other Brazilian studies which showed that the prevalence rates of abdominal adiposity have been increasing over the last decades in this age range, varying from $27.3 \%$ to $47.6 \%$ (22). When compared to international findings, these values are higher than those of Spanish (11.6\%) (23) and Polish $(34,5 \%)(24)$. The accumulation of abdominal fat is known to be more dangerous by being more functionally active than the accumulation of subcutaneous fat and by having higher rates of lipolysis and being associated with insulin resistance $(25)$.

The accumulation of adipose tissue detected by WC measurement proved to have an early influence on the blood pressure of the students. Previously published studies on adolescents have also identified associations between abdominal obesity and high blood pressure, although, when considered separately, blood pressure did not change over time. Comparison of the two measures has pointed out that WC measurement is an important tool for the assessment of visceral obesity since it is easy to obtain and is an important predictor of cardiovascular risk in adolescents, appearing to better estimate intra-abdominal fat than the BMI (26).

On average, $25 \%$ of the adolescents evaluated here in the two samples showed pre- or full arterial hypertension. In a meta-analysis study, Gonçalves and cols. (27) reported an $8.0 \%$ prevalence of systemic arterial hypertension among adolescents, and the ERICA (5) study reported a value of $9.6 \%$, with a $28.4 \%$ prevalence among obese subjects. Several studies conducted in various Brazilian cities have reported different prevalence values of arterial hypertension among young persons. In Belo Horizonte, Ribeiro and cols. (20) detected a prevalence of $12 \%$, in Rio de Janeiro (28) the prevalence was $19.4 \%$ and in Londrina it was $9 \%$ (13). We believe that the measurement of blood pressure on a single occasion may explain these different values. Although several studies perform only one measurement in order to diagnose arterial hypertension, the recommendation is to perform more than one since measurements obtained on a single occasion may not reflect the real values of adolescents, suggesting that multiple measurements on different occasion may have a reducing effect on arterial hypertension (29). In the present study, the same technique and interpretation of 
the results were used for both samples, supporting the reliability of the results.

In this study, we did not find an increase in blood glucose when comparing the samples. In a longitudinal study, Reinehr and cols. (29) reported that hyperglycemia can be the main abnormality among obese children and adolescents, thus contributing to dyslipidemia. The chronic inflammation caused by adipose tissue plus insulin resistance over time may trigger micro- and macrovascular complications due to vascular remodeling with the proliferation of cells of the vascular musculature, i.e., endothelial dysfunction, macrophage migration, increased platelet aggregation with consequent thrombus formation, and the risk to develop diabetes mellitus (30).

In Brazil, the prevalence of adolescents with insufficient levels of physical activity ranges from 39\% to $93,5 \%(31)$. In the present study, the prevalence of physical inactivity was $32.9 \%$ in 2000 , as opposed to double this value $(66.5 \%)$ in 2015 . With a similar study design and instrument for assessment, two student samples were evaluated in the city of Pelotas in 2005 and 2012, with a respective prevalence of physical inactivity of 69.6 and $69.9 \%$ (32). We believe that the 15 -year interval between our studies was decisive for the notable changes in the practice of physical activity by the adolescents. In study, Beck and cols. (19) detected a prevalence of physical inactivity was $61,2 \%$. Among the possible causes of the increased rates of physical inactivity is the process of urbanization. The arrival of the technology era and the facilities due to modernization may have influenced the change in life style of the population, especially regarding the practice of physical activity.

In the present study, in contrast to a decrease in tobacco consumption, alcohol consumption increased exponentially among the adolescents studied from $6.9 \%$ to $24.2 \%$. Data obtained in the large Brazilian studies, PeNSE (National Survey of School Health) (33), conducted on Brazilian schoolchildren have shown that $26.1 \%$ of the subjects interviewed, presented risk behaviors regarding the regular consumption of alcoholic beverages. In addition to having a social impact, alcohol consumption in this age range is a source of concern because of damage to neurocognitive development and the potentiation of the risk of cardiovascular diseases.

Studies with objectives similar to those of the present one have warned that if the obesity trends are maintained in the long term, the prevalence for 2015 will be 11.3 million, with 427 thousand having pre-diabetes, 150 thousand type 2 diabetes, one million arterial hypertension, and 1.4 million stage 1 nonalcoholic hepatic steatosis (34). In an attempt to control the obesity epidemic, several countries, including Brazil, have adopted policies for the control of weight gain among children and adolescents. The Brazilian Association for the Study of Obesity and Metabolic Syndrome (Abeso) (35) recommends weight monitoring for children and adolescents based on BMI and WC in addition to the encouragement of the practice of physical activity and of the reduction of calorie intake.

In summary, we conclude that cardiovascular risk factors can originate in adolescence and, despite the implementation of various actions against obesity, still represent a challenge regarding the transformation of evidence into effective practices and the establishment of directives, especially in low income countries like Brazil. As a limitation of the present investigation is the different ways of assessing blood glucose in both periods. Finally, we emphasize further studies are needed aiming at the early prevention of cardiovascular diseases in this age range.

Acknowledgments: to the Municipal Secretary of Education of Marília/SP and the schools for their support in conducting studies. To the Coordination for the Improvement of Higher Education Personnel (Capes in the Portuguese acronym), for the scholarship granted for the execution of the study.

Funding statement: financial support from the Coordination of Improvement of Higher Level Personnel (Capes).

Disclosure: no potential conflict of interest relevant to this article was reported.

\section{REFERENCES}

1. Brasil. Ministério da Saúde. Secretaria de Vigilância em Saúde. Indicadores de mortalidade [Internet]. Brasília: Ministério da Saúde; 2006. [cited 2019 Aug 7]. Available from: http://tabnet. datasus.gov.br/cgi/tabcgi.exe?idb2006/c04.def.

2. World Health Organization (WHO). The world health report 2002 - Reducing risks, promoting health life [Internet]. Geneva: WHO; 2002 [cited 2019 set 1]. Available from: http://www.who.int/ whr/2002/media_centre/en/index.html.

3. Instituto Brasileiro de Geografia e Estatística. Pesquisa de Orçamentos Familiares 2002-2003: antropometria e análise do estado nutricional de crianças e adolescentes no Brasil. Rio de Janeiro: IBGE; 2006.

4. Ministério da Saúde. Centro Brasileiro de Análise e Planejamento. Pesquisa Nacional de Demografia e Saúde da Criança e da Mulher 
2006: dimensões do processo reprodutivo e de saúde da criança. Estatística e Informação em Saúde [internet]. Brasília: Ministério da Saúde; 2009. Available from: http://bvsms.saude.gov.br/bvs/ pnds/index.php.

5. Bloch KV, Klein CH, Szklo M, Kuschnir MCC, Abreu GA, Barufaldi LA, et al. ERICA: prevalências de hipertensão arterial e obesidade em adolescentes brasileiros. Rev Saúde Pública. 2016;50(Supl 1).

6. Lean MEJ, Han TS, Morrison CE. Waist circumference as a measure for indicating need for weight management. BMJ. 1995;311 (6998):158-61.

7. de Onis M, Onyang AW, Borghi E, Siyam A, Nishida C, Siekmann J. Development of aWHO growth reference for school-aged children and adolescents. Bull World Health Organ. 2007;85(9):660-7.

8. Zimmet P, Alberti G, Kaufman F, Tajima N, Silink M, Arslanian S, et al. The metabolic syndrome in children and adolescents: the IDF consensus [Internet]. Brussels: International Diabetes Federation; 2009 [cited 2019 Oct 21]. Available at: http://www.idf.org/webdata/ docs/Mets_definition_children.pdf.

9. National High Blood Pressure Education Program Working Group on High Blood Pressure in Children and Adolescents. The Fourth Report on the Diagnosis, Evaluation, and Treatment of High Blood Pressure in Children and Adolescents. Pediatrics. 2004:114(2):555-76.

10. American Diabetes Association. Tests of glycemia in diabetes. Diabetes Care. 2004:27(1):91-3.

11. Matsudo S, Araujo T, Matsudo V, Andrade D, Andrade E, Oliveira $C$, et al. Questionário internacional de atividade física (IPAQ): estudo de validade e reprodutibilidade no Brasil. Rev Bras Ativ Fis Saúde. 2001;6(2):5-12.

12. Rosenbloom AL, Silverstein JH, Amemiya $S$, Zeitler $P$, Klingensmith $\mathrm{G}$. International society for pediatric and adolescent diabetes. ISPAD clinical practice consensus guidelines 2007-2007. Type 2 diabetes mellitus in the child and adolescent. Pediatr Diabetes. 2008;9(5):512-26.

13. Guedes DP, Guedes JEP, Barbosa DS, Oliveira JÁ, Stanganelli LCR. Fatores de Risco Cardiovasculares em Adolescentes: Indicadores Biológicos e Comportamentais Cardiovascular. Arq Bras Cardiol. 2006;86(6):439-50.

14. Sanchez A, Norman GJ, Sallis JF, Calfas KJ, Cella J, Patrick $\mathrm{K}$. Patterns and correlates of physical activity and nutrition behaviors in adolescents. Am J Prev Med. 2007;32(2):124-30.

15. Hardy LL, Grunseit A, Khambalia A, Bell C, Wolfenden L, Milat AJ. Co-occurrence of Obesogenic Risk Factors Among Adolescents. J Adolesc Health. 2012;51(3):265-71.

16. Plotnikoff RC, Karunamuni N, Spence JC, Storey K, Forbes L, Raine $\mathrm{K}$, et al. Chronic disease-related lifestyle risk factors in a sample of Canadian adolescents. J Adolesc Health. 2009;44(6):606-9.

17. Brasil. Ministério da Saúde. Secretaria de Atenção à Saúde. Instituto Nacional de Câncer. Coordenação de Prevenção e Vigilância. A situação do câncer no Brasil. [Internet]. Rio de Janeiro: INAC; 2006 [cited 2019 Nov 12]. Available from: http:// bvsms.saude.gov.br/bvs/publicacoes/situacao_cancer_brasil.pdf.

18. Rezende LFM, Arnold M, Rabacow FM, Levy RB, Claro MR, Geovannucci $E$, et al. The increasing burden of cancer attributable to high body mass index in Brazil. Cancer Epidemiol. 2018;54:63-70.

19. Beck CC, Lopes AS, Giuliano ICB, Borgatto AF. Fatores de risco cardiovascular em adolescentes de município do sul do Brasil: prevalência e associações com variáveis sociodemográficas. Rev Bras Epidemiol. 2011;14(1):36-49.
20. Ribeiro RQC, Lotufo PA, Lamounier JA, Oliveira RG, Soares JF, Botter DA. Fatores adicionais de risco cardiovasculares associados ao excesso de peso em crianças e adolescentes: o estudo do coração de Belo Horizonte. Arq Bras Cardiol. 2006;86(6):408-18.

21. Ogden $C L$, Carroll MD, Curtin LR, McDowell MA, Tabak CJ, Flegal KM. Prevalence of overweight and obesity in the United States, 1999-2004. JAMA. 2006;295(13):1549-55.

22. Rinaldi AE, Gabriel GF, Moreto F, Corrente JE, McLellan KC, Burini RC. Dietary factors associated with metabolic syndrome and its components in overweight and obese Brazilian schoolchildren: a cross-sectional study. Diabetol Metab Syndr. 2016;8(1):58.

23. Schroder H, Ribas L, Koebnick C, Funtikova A, Gomez SF, Fito M, et al. Prevalence of abdominal obesity in Spanish children and adolescents. Do we need waist circumference measurements in pediatric practice? PLoS One. 2014(1);9:875-49.

24. Piotrowska E, Broniecka A, Wyka J, et al. Influence of non-dietary factors on the prevalence of abdominal obesity as a major component of the metabolic syndrome among 17-18-year-old youth. Rocz Panstw Zakl Hig. 2015;66(1):85-92.

25. Welborn TA, Dhaliwal SS. Preferred clinical measures of central obesity for predicting mortality. Eur J Clin Nutr. 2007;61(12):1373-9.

26. Gonçalves VSS, Galvão TF, Andrade KRC, Dutra ES, Bertolin MNT, Carvalho KMB, et al. Prevalência de hipertensão arterial entre adolescentes: revisão sistemática e metanálise. Rev Saúde Pública. 2016;50:27.

27. Corrêa-Neto VG, Sperandei S, Silva LAI, Maranhão-Neto GA, Palma A. Hipertensão Arterial em adolescentes do Rio de Janeiro: prevalência e associação com atividade física e obesidade. Ciênc Saúde Coletiva. 2014;19(6):1699-9.

28. Chiolero A, Bovet P, Paredis G, Paccaud F. Has blood pressure increased in children in response to the obesity epidemic? Pediatrics. 2007;119(3):544-53.

29. Reinehr T, de Sousa G, Andler W. Longitudinal analyses among overweight, insulin resistance, and cardiovascular risk factors in children. Obes Res. 2005;13(10):1824-33.

30. Tassitano RM, Bezerra J, Tenório MCM, Colares V, Barros MVG, Hallal PC. Atividade física em adolescentes brasileiros: uma revisão sistemática. Rev Bras Cineantropom Desempenho Hum. 2007;9(1):55-60.

31. Coll Cde V, Knuth AG, Bastos JP, Hallal PC, Bertoldi AD. Time trends of physical activity among Brazilian adolescents over a 7-year period. J Adolesc Health. 2014;54(2):209-13.

32. Instituto Brasileiro de Geografia e Estatística. Pesquisa Nacional de Saúde do Escolar (PeNSE). Rio de Janeiro: IBGE; 2015 [cited 2019 Nov 25]. Available from: https://biblioteca.ibge.gov.br/ visualizacao/livros/liv97870.pdf.

33. Stranges S, WuT, Dorn JM, Freudenheim JL, Muti P, Farinaro E, et al. Relationship of alcohol drink pattern to risk of hypertension: a population based-study. Hypertension. 2004;44(6):813-9.

34. Associação Brasileira para o Estudo da Obesidade e da Síndrome Metabólica/Abeso. Mapa da obesidade [Internet]. São Paulo (SP); 2015 [cited 2019 Nov 25]. Available from: http://www.abeso.org. br/atitude-saudavel/mapa-obesidade.

35. Associação Brasileira para o Estudo da Obesidade e da Síndrome Metabólica/ABESO. Diretrizes brasileiras de obesidade; 2016. $4^{\text {a }}$ ed. São Paulo (SP) [cited 2019 Nov 27]. Available from: http:// www.abeso.org.br/uploads/downloads/92/57fccc403e5da.pdf. 